\title{
A indisciplina na EEEFM José Teixeira Fialho no turno vespertino
}

O presente Artigo é resultado de pesquisa realizada na EEEFM JOSÉ TEIXEIRA FIALHO, no turno vespertino, sobre um problema recorrente e frequente no contexto escolar: a indisciplina. Sua influência no cotidiano tem provocado conflitos diários e obstáculos no processo ensino-aprendizagem. Os fatores levantados após entrevista, envolvendo alunos e professores, apontam práticas e comportamentos inadequados em ambos. Concluiu-se que para haver um relacionamento equilibrado é necessário privilegiar o diálogo e repensar às práticas e comportamentos de todos.

Palavras-chave: Indisciplina; Escola; Aluno; Professor.

\section{Indiscipline at the EEEFM José Teixeira Fialho in the afternoon shift}

This Article is the result of research carried out at EEEFM JOSÉ TEIXEIRA FIALHO, in the afternoon, on a recurring and frequent problem in the school context: indiscipline. Its influence on daily life has caused daily conflicts and obstacles in the teaching-learning process. The factors raised after the interview, involving students and teachers, point to inappropriate practices and behaviors in both. It was concluded that in order to have a balanced relationship, it is necessary to privilege dialogue and rethink everyone's practices and behaviors.

Keywords: Indiscipline; School; Student; Teacher.

Topic: Pedagogia (Educação Criança e Adolescente)

Reviewed anonymously in the process of blind peer.
Received: 15/06/2020

Approved: 20/07/2020
Jailson Mauricio Pinto (iD

Centro Universitário Leonardo da Vinci, Brasi

http://lattes.cnpq.br/5630364581431753

http://orcid.org/0000-0002-4051-0051

jailsonecop@hotmail.com

Douglas Vicente do Carmo Lima

Centro Universitário Norte Capixaba, Brasil

http://lattes.cnpq.br/8496236068852285

biologiavicente14@gmail.com
Referencing this:

PINTO, J. M.; LIMA, D. V. C.. A indisciplina na EEEFM José Teixeira Fialho no turno vespertino. Humanum Sciences, v.2, n.2, p.20-32 2020. DOI: http://doi.org/10.6008/CBPC2674-6654.2020.002.0002 


\section{INTRODUÇÃO}

Sabe-se que a Educação tem inovando em diversos aspectos, métodos técnicos, proporcionando assim melhores condições de aprendizagem. Porém, observa-se que ao longo do tempo que muitas das queixas externadas pelos docentes e discentes são sobre o comportamento e práticas de ambos, em especial, no turno noturno da EEEFM José Teixeira Fialho, onde alunos e professores demonstram insatisfação, provocando conflitos diários e obstáculos no ensino-aprendizagem. Neste sentido surgem questões que para solucionar o problema poderiam nortear o caminho a ser seguido: Quais fatores prejudicam o estabelecimento de uma boa relação entre aluno $X$ professor e aluno $X$ aluno gerando situações conflitivas? A indisciplina escolar é provocada por uma deficiência do aluno ou do professor? O que está errado: 0 Método ou a falta de motivação do aluno? A didática ou a falta de perspectiva?.

O objetivo desta pesquisa é apresentar e analisar os elementos que promovem a disciplinares, bem como discutir como se processa o ensino-aprendizagem, discutir as raízes do problema e propor solução.

\section{METODOLOGIA}

\section{A indisciplina}

As literaturas mesmo que escassas tem tratado de assuntos sobre a Disciplina Escolar desde o contexto histórico aos dias atuais. Para maiores esclarecimentos do que será abordado no contexto do tema sobre a indisciplina escolar, achou-se por bem conceituar e separar termos entre 'Disciplina' e 'Indisciplina' dando ênfase a etimologia do significado, e discuti-la a partir do enfoque de outros autores que estudaram o assunto. Segundo Aurélio (2001):

Disciplina regime de ordem imposta ou mesmo consentida. 2. ordem que convém ao bom funcionamento de uma organização. 3. relações de subordinação do aluno ao mestre. 4. submissão a um regulamento. 5. qualquer ramo do conhecimento. 6. matéria de ensino. Indisciplina procedimento, ato ou dito contrário à disciplina.

Segundo Teles (1992),

A disciplina enquanto regime de ordem imposta ou livremente consentida que convém ao funcionamento regular de uma organização, implicaria na observância a preceitos ou normas estabelecidas. A violência, por sua vez, seria caracterizada por qualquer ato violento que, no sentido jurídico, provocaria, pelo uso da força, um constrangimento físico ou moral.

A partir destas colocações surgem alguns questionamentos. Será que em educação poderíamos debater sobre esses conceitos, usando as mesmas concepções? Será que a indisciplina e a violência são sempre indesejáveis, ou teríamos de considerar a ambiguidade desses termos? Essas questões levaram a uma reflexão sobre a duplicidade sempre presente nas práticas sociais e que nos obriga a considerar não apenas as regras do jogo institucional, mas também outras regras que, de modo velado, perpassam o cotidiano escolar.

A escola, enquanto espaço onde ocorre a manifestação de violência e de indisciplina, é percorrida por um movimento ambíguo: de um lado, pelas ações que visam ao cumprimento das leis e das normas determinadas pelos órgãos centrais, e, de outro, pela dinâmica dos seus grupos internos que estabelecem 
interações, rupturas e permitem a troca de ideias, palavras e sentimentos numa fusão provisória e conflitual.

A instituição escolar não pode ser vista apenas como reflexo da opressão, da violência, dos conflitos que acontecem na sociedade. É importante argumentar que as escolas também produzem sua própria violência e sua própria indisciplina. Segundo Nidelcoff (1999),

Para dar conta de algumas formas de violência e de indisciplina que dinamizam a vida cotidiana da escola, é preciso apreender, na ambiguidade desses fenômenos, seus modos específicos de manifestação.

Não se tem como objetivo valorizar esteticamente a violência, nem defender uma escola sem regras, mas apontar a existência de uma lógica interna aos fatos que ofereça uma pista para encontrarmos alternativas pedagógicas de negociação com os conflitos. Ainda segundo Nidelcoff (1999),

\begin{abstract}
A escola como qualquer outra instituição, está planificada para que as pessoas sejam todas iguais. Há quem afirme: "quanto mais igual, mais fácil de dirigir". A homogeneização é exercida por meio de mecanismos disciplinares, ou seja, de atividades que esquadrinham o tempo, o espaço, o movimento, os gestos e as atitudes dos alunos, dos professores, dos diretores, impondo aos corpos uma atitude de submissão e docilidade.
\end{abstract}

Assim como a escola tem esse poder de dominação que não tolera as diferenças, ela também é recortada por formas de resistência. Compreender esta situação implica em aceitar a escola como um lugar que se expressa numa extrema tensão entre forças antagônicas.

Como a pluralidade das ações aí presentes não se reduz à uniformidade, o princípio da homogeneização, imposto pela escola, não se coloca tranquilamente, pois ele repousa numa inquietação frente à existência dos diferentes grupos. A disciplina imposta, ao desconsiderar, por exemplo, o modo como são partilhados os espaços, o tempo, as relações entre os alunos, gera uma reação que explode na indisciplina incontrolável ou na violência.

\title{
DISCUSSÃO TEÓRICA
}

\section{Tendências pedagógicas}

Ao longo da história da Educação no contexto mundial, as relações entre professor e aluno sempre foram um dos pontos determinantes para compreender como se dava ou se dá o processo ensino aprendizagem em cada forma de organização escolar de cada época, consequentemente tanto a disciplina quanto a indisciplina, aparecem como marca registrada para o entendimento de como essas tendências educacionais foram desenvolvidas nas escolas e as formas de tratamento método, ou outros destinados ao controle das mesmas, acabavam por consequência sendo fator preponderante para o entendimento da indisciplina em si mesma.

Abordar-se à neste capítulo, as tendências educacionais a partir das concepções de Libâneo (1995), considerando que este autor é um referencial bibliográfico básico a todos os cursos de formação de professores, portanto são teorias que a maioria dos professores já teve acesso. Libâneo (1995) organizou o conjunto das pedagogias em dois grupos: o grupo 1 compreendendo a Pedagogia Liberal: Pedagogia tradicional, Renovada Progressista, Renovada Não-Diretiva; Tecnicista; e o grupo 2 compreendendo Pedagogia Progressista: Libertadora, Libertária e Crítico Social dos conteúdos. 


\section{Pedagogia Liberal}

Segundo Libâneo (1995) O termo liberal não tem o sentido de "avançado", "democrático", "aberto", como costuma ser usado. A educação brasileira, pelo menos nos últimos cinquenta e cinco anos, tem sido marcada pelas tendências liberais, nas suas formas ora conservadora, ora renovada. A pedagogia Liberal, portanto, é uma manifestação própria de uma sociedade baseada na propriedade privada dos meios de produção. Essa escola tem por função preparar os indivíduos para o desempenho de papéis sociais, de acordo com as aptidões individuais, por isso os indivíduos precisam aprender a se adaptar aos valores e às normas vigentes na sociedade de classes através do desenvolvimento da cultura individual.

Historicamente, a educação liberal iniciou-se com a pedagogia tradicional e, por razões de recomposição da hegemonia da burguesia, evoluiu para a pedagogia renovada (também denominada escola nova ativa). A característica da pedagogia liberal é acentuar o ensino humanístico, de cultura geral, no qual o aluno é educado para atingir, pelo próprio esforço, sua plena realização como pessoa. Os conceitos, os procedimentos didáticos, a relação com o cotidiano do aluno não se relaciona com as realidades sociais.

A palavra do professor é superior a tudo e a todos e as regras são impostas com base exclusivamente no intelectual. Ainda segundo Libâneo (1999). A escola renovada propõe um ensino que valorize a autoeducação (o aluno como sujeito do conhecimento), a experiência direta sobre o meio pela atividade; um ensino centrado no aluno e no grupo. A tendência liberal renovada apresenta-se, entre nós, em duas vertentes distintas: a renovada progressista, ou pragmatista; a renovada não-direta orientada para os objetivos de autorrealização e para relações interpessoais.

\section{Tendência Liberal Tradicional}

De acordo com Libâneo (1995), “A atuação da escola consiste na reparação intelectual e moral dos alunos para assumir sua posição na sociedade. O compromisso da escola é com a cultura, os problemas sociais pertencem à sociedade". Os menos capazes devem lutar para superar suas dificuldades e conquistar seu lugar junto aos mais capazes. As matérias de estudo visam a preparar o aluno para a vida são determinadas pela sociedade e ordenadas na legislação. Os conteúdos são separados da experiência do aluno e das realidades sociais, valendo pelo valor intelectual, a razão pela qual a pedagogia tradicional é criticada como intelectualista e, às vezes, como enciclopédica. Os métodos baseiam-se na exposição verbal da matéria e/ ou demonstração. Tanto a exposição quanto a análise são feitas pelo professor. A ênfase nos exercícios, na repetição de conceitos ou fórmulas na memorização visa disciplinar a mente e formar hábitos.

A relação professor-aluno, segundo Libâneo (1995):

Predomina a autoridade do professor que exige atitude receptiva dos alunos e impede qualquer comunicação entre eles no decorrer da aula. O professor transmite o conteúdo na forma de verdade a ser absorvida; em consequência, a disciplina imposta é o meio mais eficaz para assegurar a atenção e o silêncio.

O ensino consiste em repassar o conhecimento para o espírito da criança e acompanhada de uma outra: a de que a capacidade de assimilação da criança é idêntica à do adulto, apenas menos desenvolvida. A aprendizagem, assim, é receptiva e mecânica, para o que se recorre frequentemente à coação. A avaliação 
se dá por verificações de curto prazo (interrogatórios orais exercícios de casa). O esforço é, em geral, negativo (punição, notas baixas, apelos aos pais); às vezes, é positivo (emulação e classificações).

\section{Tendência Liberal Renovada Progressista}

Na tendência Liberal Renovada progressista segundo Libâneo (1995):

A finalidade da escola é adequar os alunos a suas necessidades individuais e ao meio social e, para isso, ela deve se organizar de forma a retratar, o quanto possível, a vida. Todo ser dispõe, dentro de si mesmo, de mecanismos de adaptação progressiva ao meio e de uma consequente integração dessas formas de adaptação no comportamento.

O conhecimento resulta da ação a partir dos interesses e necessidades, os conteúdos de ensino são estabelecidos em função de experiências que o sujeito vivencia frente a desafios cognitivos e situações problemáticas. Valorizam-se mais os processos mentais e habilidades cognitivas do que a conteúdos organizados racionalmente. Trata-se de 'aprender a aprender'. A ideia de 'aprender fazendo' está sempre presente.

Valorizando-se as tentativas experimentais, a pesquisa, a descoberta, o estudo do meio natural e social, acentua-se a importância do trabalho em grupo não apenas como técnica, mais como condição básica do desenvolvimento mental. Não há lugar privilegiado para o professor, antes, seu papel é auxiliar o desenvolvimento livre e espontâneo da criança. Ainda Segundo Libâneo (1995):

A disciplina surge de uma tomada de consciência dos limites da vida grupal; assim, aluno disciplinado é aquele que é solidário, participante, respeitador das regras do grupo. Para se garantir um clima harmonioso dentro da sala de aula é indispensável um relacionamento positivo entre professores e alunos, uma forma de instaurar a 'vivência democrática' tal qual deve ser a vida em sociedade.

Aprender se torna uma atividade de descoberta, é uma autoaprendizagem, sendo o ambiente apenas o meio estimulador. A avaliação é fluida e tenta ser eficaz à medida que os esforços e os êxitos são pronta e explicitamente reconhecidos pelo professor.

\section{Tendência Liberal Renovada Não-Diretiva}

Nesta tendência o papel da escola está voltado para formação de atitudes, razão pela qual deve estar mais preocupada com os problemas psicológicos do que com os pedagógicos e sociais.

Segundo Libâneo (1995):

Todo esforço está em estabelecer um clima favorável a uma mudança dentro do indivíduo, isto é, a uma adequação pessoal às solicitações do ambiente. Os métodos usuais são dispensados, prevalecendo quase que exclusivamente o esforço do professor em desenvolver um estilo próprio para facilitar a aprendizagem dos alunos. Propõe uma educação centrada no aluno, visando formar sua personalidade através da vivência de experiências significativas que the permitam desenvolver características inerentes à sua natureza. O professor é considerado especialista em relações humanas, a fim de garantir o clima de relacionamento pessoal e autêntico.

Quando o professor estreita os laços, utiliza exemplos do cotidiano dos alunos para explicar os conteúdos; facilmente esse professor obtém a atenção e admiração dos alunos facilitando assim o clima em sala de aula e influenciando nas ações pessoais dos alunos.

Para Libâneo (1995): 
Ausentar-se é a melhor forma de respeito e aceitação plena do aluno. Toda intervenção é ameaçadora, inibidora da aprendizagem. A motivação resulta do desejo de adequação pessoal na busca da autorrealização; é, portanto, um ato interno. Aprender, portanto, é modificar suas próprias percepções, daí que apenas se aprende o que estiver significativamente relacionado com essas percepções. Resulta que a retenção se dá pela relevância do aprendido em relação ao 'eu', ou seja, o que não está envolvido com o 'eu' não é retido e nem transferido". Portanto, a avaliação escolar perde inteiramente o sentido, privilegiando-se a autoavaliação.

Ao propor uma autoavaliação o professor obriga de certa forma o aluno a se analisar, olhar para si e tomar consciência do seu envolvimento com os conteúdos apreendidos ou não.

\section{Tendência Liberal Tecnicista}

A escola funciona como modeladora do comportamento humano, através de técnicas específicas. À educação escolar compete organizar o processo de aquisição de habilidades, atitudes e conhecimentos específicos, úteis e necessários para os indivíduos se integrem na máquina do sistema social global. Atua no aperfeiçoamento de ordem social vigente (o sistema capitalista), articulando-se diretamente como o sistema produtivo; para tanto, emprega a ciência da mudança de comportamento, ou seja, a tecnologia comportamental.

Os métodos de Ensino consistem nos procedimentos e técnicas necessários ao arranjo e controle das condições ambientais que assegurem a transmissão/recepção de informações. Se a primeira tarefa do professor é modelar respostas apropriadas aos objetivos instrucionais, a principal é conseguir o comportamento adequado pelo controle do ensino; daí a importância da tecnologia educacional.

Segundo Libâneo (1995):

São relações estruturadas e objetivas, com papéis bem definidos: o professor administra as condições de transmissão da matéria, conforme um sistema instrucional eficiente e efetivo em termos de resultados da aprendizagem; o aluno recebe, aprende e fixa as informações. O professor é apenas um elo de ligação entre a verdade cientifica e o aluno, cabendo-Ihe empregar o sistema instrucional previsto. $O$ aluno é um indivíduo responsivo, não participa da elaboração do programa educacional. Ambos são espectadores frente à verdade objetiva. A comunicação professor-aluno tem um sentido exclusivamente técnico, que é o de garantir a eficácia da transmissão do conhecimento.

\section{Tendência Progressista Libertadora}

Aqui o importante não é a transmissão dos conteúdos específicos, mas sim despertar uma nova forma da relação com a experiência vivida. A transmissão de conteúdos estruturados a partir de fora é considerada como 'invasão cultural' ou 'deposito de informação', porque não emerge do saber popular.

Engaja ativamente a ambos os sujeitos do ato de conhecer: educador - educando e educando educador. O 'grupo de discussão', a quem cabe autogerir a aprendizagem, definindo o conteúdo e a dinâmica das atividades. Segundo Libâneo (1995):

O professor é um animador que, por princípio, deve 'descer' ao nível dos alunos, adaptandose às suas características. Deve caminhar 'junto', intervir mínimo indispensável, embora não se furte, quando necessário, a fornecer uma informação mais sistematizada.

Codificação-decodificação, problematização da situação - permitirão aos educandos um esforço de 
compreensão do 'vivido', até chegar a um nível mais crítico de conhecimento da sua realidade. Admite-se a avaliação da prática vivenciada entre educador - educandos no processo de grupo e, às vezes, a autoavaliação feita em termos dos compromissos assumidos com a prática social.

Ainda segundo Libâneo (1995):

No diálogo, como método básico, a relação é horizontal, onde educador e educandos se posicionam como sujeitos do ato do conhecimento. $\mathrm{O}$ critério de bom relacionamento é a total identificação com o povo, sem o que a relação pedagógica perde consistência. Toda relação de autoridade é eliminada e aprender passa a ser um conhecimento da realidade, isto é, da situação real vivida pelo educando, e só tem sentido se resulta de uma aproximação crítica dessa realidade. O que é aprendido não decorre de uma imposição ou memorização, mas do nível crítico de conhecimento, ao qual se chega pelo processo de compreensão, reflexão e crítica.

\section{Tendência Progressista Libertária}

A transformação proposta pela Pedagogia Libertária é apurar o senso crítico dos alunos de forma tal que todos sejam capazes de levar para sua vida pessoal atitudes democráticas. Segundo Libâneo (1995):

A pedagogia libertária espera que a escola exerça uma transformação na personalidade dos alunos num sentido libertário e autogestionário. A ideia básica é introduzir modificações institucionais, a partir dos níveis subalternos que, em seguida, vão 'contaminando' todo o sistema. A escola instituirá, com base na participação grupal, mecanismos institucionais de mudança (assembleias, conselhos, eleições, reuniões, associações etc.), de tal forma que o aluno, uma vez atuando nas instituições 'externas', leve para lá tudo o que aprendeu.

A autogestão é o conteúdo e o método; resume tanto o objetivo pedagógico quanto o político. A pedagogia libertária pretende ser uma forma de resistência contra a burocracia como instrumento da ação denominadora do Estado, que tudo controla (professores, programas, provas etc.), retirando a autonomia.

As matérias são colocadas à disposição do aluno, mas não são exigidas e são instrumentos a mais, porque importante é o conhecimento que resulta das experiências vividas pelo grupo. É na vivência grupal, na forma de autogestão, que os alunos buscarão encontrar as bases mais satisfatórias de sua própria 'instituição', graças à sua própria iniciativa e sem qualquer forma de poder.

Ainda segundo Libâneo (1995):

Os alunos têm liberdade de trabalhar ou não, ficando o interesse pedagógico na dependência de suas necessidades ou das do grupo, Visa a transformar a relação professoraluno no sentido da não - diretividade, isto é, considerar desde o início a ineficácia e a nocividade de todos os métodos à base de obrigações e ameaças. Embora professor e aluno sejam desiguais e diferentes, nada impede que o professor se ponha a serviço do aluno, sem impor suas concepções e ideias. O professor é um orientador e um catalisador, ele se mistura ao grupo para uma reflexão em comum. Se os alunos são livres frente ao professor, também este é em relação aos alunos (ele pode, por exemplo, recusar-se a responder uma pergunta, permanecendo em silêncio).

Essa liberdade de decisão tem um sentido claro: se um aluno resolve não participar, o faz porque não se sente integrado, mas o grupo tem responsabilidade sobre este fato e vai se colocar a questão; quando o professor se cala diante de uma pergunta, seu silêncio tem um significado educativo que pode, por exemplo, ser uma ajuda para que o grupo assuma a resposta ou a situação criada. Em nenhum momento esses papéis do professor se confundem com o 'modelo', pois a pedagogia libertária recusa qualquer forma de poder ou autoridade. A ênfase a aprendizagem informal, via grupo, e a negação de toda forma de repressão visam a 
favorecer o desenvolvimento de pessoas livres.

\section{Tendência Progressista 'Critico - Social Dos Conteúdos'}

Neste momento, entender a tendência Progressista crítico social dos conteúdos representa ampliar a visão do mundo educacional. Segundo Libâneo (1995):

A difusão de conteúdos é a tarefa primordial. Não conteúdos abstratos, mais vivos, concretos e, portanto, indissociáveis das realidades sociais. A valorização da escola como instrumento de apropriação do saber é o melhor serviço que se presta aos interesses populares, já que a própria escola pode contribuir para eliminar a seletividade social e torná-la democrática. Se a escola é parte integrante do todo social, agir dentro dela é também agir no rumo da transformação da sociedade.

A atuação da escola consiste na preparação do aluno para o mundo adulto e suas contradições, fornecendo-lhe um instrumental, por meio da aquisição de conteúdos e da socialização, para uma participação organizada e ativa na democratização da sociedade. São os conteúdos culturais universais que se constituíram em domínios de conhecimento relativamente autônomos, incorporados pela humanidade, mas permanentemente reavaliados face às realidades sociais, embora se aceite que os conteúdos são realidades exteriores ao aluno. Os métodos de uma pedagogia crítica - social dos conteúdos não partem, de um saber artificial, depositado a partir de fora, nem do saber espontâneo, mas de uma relação direta com a experiência do aluno, confrontada com o saber trazido de fora. Para Libâneo (1995):

O trabalho docente relaciona a prática vivida pelos alunos com os conteúdos propostos pelo professor, momento em que se dará a 'ruptura' em relação à experiência pouco elaborada. Tal ruptura apenas é possível com a introdução explícita, pelo professor, dos elementos novos de análise a serem aplicados criticamente à prática. Se, como mostramos anteriormente, o conhecimento resulta de trocas que se estabelecem na interação entre o meio (natural, social, cultural) e o sujeito, sendo o professor o mediador, então a relação pedagógica consiste no provimento das condições em que professores e alunos possam colaborar para fazer progredir essas trocas. O papel do adulto é insubstituível, mas acentuase também a participação do aluno no processo.

Compreender os conteúdos através da visão da pedagogia dos conteúdos é desenvolver a capacidade de codificar as informações, o professor busca compreender o que os alunos dizem ou fazem os alunos entenderem o que os professores procuram transmitir.

\section{Os desafios da indisciplina em sala de aula e na escola}

A Indisciplina escolar é um dos grandes desafios para os educadores nos dias atuais, tanto em escolas públicas quanto nos particulares. Porém, engana-se pensando que é um problema somente no Brasil ou de Países do Terceiro Mundo. Em alguns países como a França, Japão e Estados Unidos considerados avançados em matéria de Educação, temos relatos de gangues estudantis que batem em professores, mortes em escolas americanas e japonesas, fruto da violência que leva os vários suicídios a cada ano.

Contudo, alguns especialistas fomentam que, tentar entender a indisciplina como um único caso isolado é pura ignorância, pois este caso está ligado a diversas outras questões. Para que se possa entender amplamente é preciso que se integre a outras Ciências Sociais como a Sociologia, Antropologia, Psicanálise, Ética, Política, Psicologia, Economia, História e Tecnologia da Comunicação. É preciso que se saiba que a 
Disciplina é apenas um processo da Educação Escolar, que por sua vez também é extremamente complexo e exigente.

A indisciplina não se resume somente no fato do aluno ser rebelde ou desmotivado, mas está intrinsecamente a várias outras questões. Para que haja modificação neste panorama é preciso se ter condições mínimas para a ação e uma base subjetiva que é o saber fazer. No âmbito geral tem que se resgatar o professor como sujeito do caminho a ser descoberto, e trabalhar os fatores que funcionam como obstáculos para os alunos.

A falta de interesse no estudo por parte dos alunos tem provocado inquietações, diante da constatação de inúmeras pessoas formadas, porém desempregadas ou muito mal remuneradas - Então vem a pergunta: Para que estudar? Uma vez que a escola não te garantindo o ingresso no mercado de trabalho.

Segundo Vasconcellos (1996):

A escola ficou protegida de suas contradições internas por muito tempo em função de sua relação de 'parceria' com o mercado de trabalho. Os alunos não viam sentido no que estavam fazendo, mas tinha em mente a perspectiva de uma recompensa mais tarde.

$\mathrm{Na}$ visão de alguns autores, eles pensam que os professores atuais estão esperando uma fórmula mágica para melhorar a Educação no país. Porém, o problema como muitos pensam, não é só do Sistema Político ou Educacional, e sim, de cada um que faz parte do contexto educativo.

Na pesquisa realizada, constatou-se que os problemas relacionados com a indisciplina têm diversas origens: a) Postura dos alunos: pedi licença constantemente, conversa outros assuntos, não cumpre com as tarefas, desrespeita os colegas e o professor, não usa o uniforme, usa celular durante as aulas, entre outros; b) Postura dos professore: Não planeja a aula, tem atitudes autoritárias, facilita muito, abusa do poder, não tem ética, não diversifica suas aulas, e em alguns casos não possuem habilitação; c) Estrutura familiar: participam muito pouco da vida escolar de seus filhos; d) Estrutura: Salas cheias e quentes, falta do livro didático, iluminação inadequada.

Esses elementos reforçam a importância da família como formadora da primeira identidade social, agindo como mediadora entre o indivíduo e a sociedade. É através dela que se dão os primeiros contatos com o mundo das regras e dos valores vigentes na sociedade. Os pais são as primeiras referências de autoridade, tornando-se responsáveis pelas diversas formas com que seus filhos irão lidar posteriormente com os limites impostos pela vida em sociedade. Pais que impõem limites aos filhos, favorecem atitudes indisciplinadas na escola. Com relação a isto Vasconcelos (2004) nos esclarece que:

As causas da indisciplina estão entrelaçadas com a sociedade, a família, a escola, o professor e o aluno, são problemas familiares, carências, influências da TV, de toda a mídia que articula muitas vezes a violência e a indisciplina.

Para Aquino (1996):

O Sistema tem que deixar de colocar a culpa em premissas ou hipóteses como à do aluno desrespeitador, do aluno sem limites e do aluno desinteressado e engrenar mais conceitos que permitam práticas escolares envolvendo premissas pedagógicas como o do conhecimento, da relação aluno e professor, da sala de aula e proposta de regras que permitam a convivência.

É sempre bom lembrar que um mesmo aluno indisciplinado com um professor nem sempre é 
indisciplinado com os outros. Sua indisciplina, portanto, parece ser algo que desponta ou se acentua dependendo das circunstâncias, e, por extensão, despersonalizar o nosso enfrentamento dos dilemas disciplinares. As premissas pedagógicas fundamentais para o norteamento educacional, nada mais são que o conhecimento, que é o objetivo exclusivo da ação do professor; a relação aluno e professor, que é o núcleo do trabalho pedagógico, pois conta-se com o aluno como parceiro, mas não esquecendo que o dever do professor é ensinar, assim como do aluno é aprender.

A sala de aula é um campo onde os conflitos têm de ser administrados e gerenciados com excelência profissional, pois é o local na qual a Educação Escolar acontece de fato; e por fim o contrato pedagógico que é uma regra de convivência que orienta o funcionamento da sala de aula, conhecidas e compartilhadas por todos. Cabe ao professor, com base em sua formação técnica, humana, social e política, descobrir a melhor forma para lidar com tais dificuldades, sem, no entanto, prejudicar a classe toda.

\section{Professor e indisciplina}

A Escola não é mais o que era antes. Todavia, a autoridade continua a ser necessária em qualquer grupo social estruturado. As relações entre os que detêm essa autoridade e os que a ela estão submetidos mudaram consideravelmente. O aluno espera ser considerado como pessoa, capaz de ser ouvido, capaz de compreender e de assumir as suas responsabilidades. Se até pouco tempo a superioridade e a autoridade do Professor se baseava no domínio do conhecimento científico, isso tende a desaparecer, dada a capacidade e facilidade que os alunos têm de acesso às novas tecnologias de informação, o que exige uma nova postura do professor.

Da forma como se processar é fundamental que o professor acredite no valor do ato educativo, através da sua atuação. Mais do que ninguém, tem de acreditar na Educação. Se não acredita naquilo que faz, não pode motivar ninguém. Deve assumir, de uma forma profunda, o papel essencial que desempenha na sociedade, recuperando e valorizando a sua imagem a partir duma reflexão séria do seu estado atual, das suas atitudes e dos seus comportamentos, dos seus pontos fortes e fracos, o que the permitirá descobrir formas de atuação que conduzam a um progresso e sucesso na sua prática profissional.

A resolução de conflitos disciplinares não é tarefa fácil. No entanto, sem pretender a exaustividade, serão referidas algumas estratégias. Para Estrela (1992), devem planificar-se estratégias de intervenção que levem a eliminar o comportamento desviante e a substituí-lo pelo comportamento desejado, que deve ser reforçado, sendo as seguintes as técnicas mais utilizadas: Reforço positivo dado por simples confirmação verbal ou gestual, ou por elogio ou recompensa; Auto-reforço que exige a cooperação ativa do aluno; Extinção, provocada pela ausência do reforço do comportamento que se quer suprimir, combinada com o reforço positivo do comportamento desejado; Contrato comportamental, segundo o qual o aluno se compromete a ter o comportamento desejado, em troca de algumas regalias que o professor se compromete a conceder-Ihe. Sampaio (1996) resume algumas questões-chave sobre indisciplina da seguinte maneira:

Combate-se a indisciplina na Escola através da co-responsabilização de professores, alunos e pais; a melhoria da comunicação professor-aluno é fundamental; os pais devem unir-se aos professores nesta tarefa; a Escola deve promover uma crescente atividade de natureza 
lúdica, cultural e formativa dos alunos, tanto nas aulas como nos tempos livres; os conteúdos programáticos devem adaptar-se, tanto quanto possível, aos interesses dos alunos; os professores deverão procurar perceber as razões dos comportamentos desviantes dos alunos.

Mas a indisciplina pode ser reduzida se os professores se tornarem organizadores mais eficazes da aula, se tiverem uma boa formação científico-pedagógica e uma boa capacidade relacional com os alunos. Silva (1995) apresenta um conjunto de condições que podem redundar num papel preventivo da indisciplina, por parte da Escola, entre as quais se podem destacar: Existência de professores competentes, bem motivados, com bons salários, elevado estatuto profissional e social e com tempo para se dedicarem às tarefas de ensino e formação pessoal; Elevado grau de autonomia nas suas decisões; Convicção de que todas as crianças e jovens podem aprender, embora aprendam de maneiras diferentes e a ritmos diferentes; Colaboração empenhada dos pais, comunidade e forças vivas locais.

Entre tudo o que uma das partes faz ou diz, há comportamentos que a outra parte aceita e outros que não aceita. Quando uma das partes tem um comportamento que a outra não aceita, é esta que tem um problema. Na relação professor-aluno pode ser um ou outro a ter o problema.

Se é o aluno a ter o problema, o professor deve apenas escutar ativamente. Para tal, deve ter tempo, recusar-se a ouvir o juízo de outrem, evitar pregar moral, dar soluções ou desvalorizar o aluno. Deve centrar-se sobre este, tentar compreender o que ele sente e reformular, nas suas próprias palavras, a mensagem recebida (...). Se é o professor que tem o problema, deve exprimir o sentimento que vive nesse momento, especificar o que é que, no comportamento dos alunos, o incomoda, e por que tal comportamento the causa problemas. Não deve atacar o aluno. $O$ professor pode ter que recomeçar várias vezes, expondo as suas necessidades, escutando as dos alunos, para conseguir fazer baixar o nível de resistência e, então, procurar dar solução ao problema. (NIDELCOFF, 1999)

Nesta perspectiva há a tentativa de encontrar comportamentos aceitáveis, de parte a parte, descobrindo e alargando zonas de aceitação comum, ou seja, os conflitos são vivenciados. A indisciplina produz efeitos negativos no aproveitamento escolar e na socialização dos alunos. Estes efeitos negativos exercem-se também sobre o professor, provocando nele desgaste físico e psicológico, ansiedade, fadiga, tensão, perda de eficácia educativa, diminuição de autoestima, sentimento de frustração e desânimo e "stress". Este conjunto de fatores pode levar, em último caso, ao abandono da profissão (ESTRELA, 1992).

Estes aspectos negativos atingem, sobretudo, os professores menos experientes e menos preparados pedagogicamente. $O$ professor tem dificuldade em gerir a heterogeneidade dos alunos, respeitando as suas diferenças e praticando um ensino individualizado.

Urge 'reinventar' a Escola, modernizar as suas estruturas e formas de funcionamento. Mas o lugar central cabe à formação de professores. Formação que sugira práticas alternativas e que ajude os professores a lidar com a heterogeneidade. Formação que proporcione alteração dos modos de organização pedagógica que, ainda que não seja suficiente para resolver todos os conflitos, possa contribuir "para tornar a Escola um lugar de vida e de aprendizagem mais interessante e produtiva e fazer redescobrir o prazer de se gostar dela" (BARROSO, 1995). Formação que os prepare para uma Escola com as difíceis e desafiantes exigências culturais, sociais e educativas dos tempos que correm.

No que se refere à disciplina, a Escola terá que ser um espaço onde se cultiva o espírito humanista, a 
tolerância ideológica e um salutar e interveniente espírito de cidadania.

\section{CONCLUSÕES}

A educação se transmite em qualquer lugar dentro ou fora do ambiente escolar, onde existe alguém que ensine e alguém disponível para aprender. Professor e aluno são os protagonistas do palco pedagógico, é entre eles que as cenas se desenrolam e finalmente se concretizam. Aprendizagem e disciplina estão envolvidas com estes personagens como pano de fundo essenciais para levar a bom termo o ato educacional.

Entretanto não se pode pensar nestes protagonistas descartando os aspectos familiar e social. Neste sentido, a estruturação escolar não poderá ser pensada apartada da família. Em verdade, são elas as duas instituições responsáveis pelo que denomina educação num sentido amplo. A indisciplina instalada revela então, um sintoma de relações familiares desagregadoras incapazes de realizar a contento sua parcela no trabalho educacional. A educação não é tão somente responsabilidade da escola.

Percebe-se que o papel da escola é relevante, não para compensar carências afetivas e disciplinares da família, mas sim de possibilitar transformações e desencadear novos processos de desenvolvimento e comportamento. Cabe ressaltar, então que se a família, a sociedade em si e os desmandos de alguns professores são os maiores culpados da indisciplina escolar, entra aí a atuação do professor como agente de possível transformação. A saída possível está mesmo no coração da relação professor-aluno, isto é, nos nossos vínculos cotidiano e, principalmente na maneira com que nos posicionamos perante o outro.

É papel do professor, criar junto com aluno, um ambiente cooperativo e fazer com que ambos compreenderam a sua importância recuperando-se assim à autoestima nos alunos. Vale lembrar que guardadas as especificidades das atribuições de agente e clientela, ambos são parceiros de um mesmo jogo. Devem-se deixar de lado os maiores rivais, a ignorância, a pouca perplexidade e o conformismo de achar que nada é possível e que somos agentes de transformação. Agora cabe necessariamente que haja união de ciências com a pedagogia e psicologia para tentar usar ferramentas que permitem averiguar os problemas e transformá-lo em compromisso com a identidade do cidadão. $O$ diálogo ainda é o melhor remédio.

Enfim, o ofício docente necessita de negociações constantes, quer com relações às estratégias de ensino, de avaliação, de objetivos, quer com relação à disciplina. Pois está se imposta autoritariamente, o aluno jamais se sentirá obrigado a cumpri-la, e a indisciplina poderá ser um protesto em relação à autoridade e a consequência falta de carinho, afetividade e compreensão.

\section{REFERÊNCIAS}

AQUINO, J. G.. Indisciplina na escola. São Paulo: Sumus, 1996.

BARROSO, J.. Organização Pedagógica e Disciplina Escolar Ä Uma Abordagem Sócio-Histórica. In: COLÓQUIO, EDUCAÇÃO E SOCIEDADE. Anais. Lisboa: Fundação Calouste Gulbenkian, 1995.

ESTRELA, M. T.. Relação Pedagógica, Disciplina e Indisciplina na Aula. Porto: Porto Ltda., 1992.
LIBÂNEO, J. C.. Tendências Democráticas na prática Escolar. 1995.

NIDELCOFF, M. T.. A Escola e a Compreensão da Realidade. São Paulo: Brasiliense,1999.

SAMPAIO, D.. Voltei à Escola. Lisboa: Caminho, 1996.

SILVA, J. J. R. F.. Violência Ä A Escola e o seu Papel. In: COLÓQUIO, EDUCAÇÃO E SOCIEDADE, 10. Anais. Lisboa: Fundação Calouste Gulbenkian, 1995. 
TELES, M. L. S.. Educação: a revolução necessária. Petrópolis: Vozes, 1992.
VASCONCELLOS, C. S.. Disciplina: Construção da disciplina consciente e interativa em sala de aula e na escola. Educação \& Sociedade, v.20, n.66, 1996.

A CBPC - Companhia Brasileira de Produção Científica (CNPJ: 11.221.422/0001-03) detém os direitos materiais desta publicação. Os direitos referem-se à publicação do trabalho em qualquer parte do mundo, incluindo os direitos às renovações, expansões e disseminações da contribuição, bem como outros direitos subsidiários. Todos os trabalhos publicados eletronicamente poderão posteriormente ser publicados em coletâneas impressas sob coordenação da Sapientiae Publishing, da Companhia Brasileira de Produção Científica e seus parceiros autorizados. Os (as) autores (as) preservam os direitos autorais, mas não têm permissão para a publicação da contribuição em outro meio, impresso ou digital, em português ou em tradução. 